\title{
Faecal chymotrypsin concentrations in neonates with cystic fibrosis and healthy controls
}

\author{
G A BROWN, R B HALLIDAY, P J TURNER, AND C A SMALLEY* \\ Institute of Child Health, University of Birmingham and *Selly Oak Hospital, Birmingham
}

SUMMARY Specimens of meconium and random stools were collected sequentially from 25 healthy newborn babies over the first 8-14 days of life. The stool chymotrypsin concentrations increased from birth to a maximum at 4 days of age and then fell again over the next four days. The lowest individual stool concentrations either side of the four day peak were both, coincidentally, $120 \mu \mathrm{g} / \mathrm{g}$ stool. In a second group of 22 newborn babies suspected of meconium ileus and later confirmed to have cystic fibrosis, faecal chymotrypsin concentrations were all appreciably reduced. In eight babies, also with suspected meconium ileus but with negative sweat tests, chymotrypsin concentrations were within the healthy newborn range.

Measuring faecal chymotrypsin concentrations is a reliable procedure for identifying pancreatic exocrine insufficiency in the newborn.

Intraduodenal tests of pancreatic exocrine function are invasive, technically difficult, and expensive and many alternative tests have been suggested. One of the alternatives proposed, the measurement of pancreatic proteolytic enzymes in faeces, has produced several validation studies in adults showing significant positive correlations between pancreatic proteolytic enzyme secretion and faecal excretion. ${ }^{1-3} \mathrm{~A}$ more recent study in children produced a highly significant positive correlation between the pancreatic chymotrypsin secretion rate into the duodenum after pancreozymin stimulation and the mean faecal chymotrypsin concentration of three random stools. ${ }^{4}$ It also showed, using a single random stool, that chymotrypsin concentration was profoundly depressed or absent in 46 children with clinical malabsorption due to cystic fibrosis.

Many children with cystic fibrosis are now identified in the neonatal period but the diagnosis may not be confirmed by sweat testing for several weeks because of the poor sweat excretion rate of the neonate. Until that time the diagnosis must remain presumptive but the demonstration of pancreatic exocrine insufficiency would be strong corroborative evidence in favour of the diagnosis and would provide a sound basis for the immediate start of pancreatic enzyme replacement. Only one detailed study has been reported on faecal chymotrypsin excretion in healthy children in this age group 5 and there are no similar data on chymotrypsin excretion in the newborn with cystic fibrosis. In this report we present a reference range for random stool chymotrypsin concentrations in the healthy neonate and data from a second group of neonates with suspected meconium ileus, three quarters of whom were subsequently shown to have cystic fibrosis.

\section{Patients and methods}

\section{HEALTHY NEONATES}

Twenty five newborn babies were admitted to the study on delivery. Seven of the 25 babies were born preterm with gestational ages of 32-36 weeks. Five of the babies were breast fed. The remainder received formula at intervals of four hours throughout the day or more often in the case of the lower birthweight babies. All formula fed babies received body weight related milk volumes. Birth weights ranged from 1720 to $3840 \mathrm{~g}$. Four of the term babies and two of the preterm babies had birth weights below the 10th centile for the gestational age.

Random meconium and stool samples were collected at least every other day from each baby during their stay in the maternity unit. A total of 156 samples were obtained, the earliest specimen being collected at three hours after birth, and the latest at 336 hours (14 days). The number of stools collected from the individual baby varied, the smallest num- 
ber collected from a single baby being four samples and the largest number eight (median six). The collection period covered the transition from the excretion of dark green-brown pigmented meconium to the bright yellow pigmentation of faeces. Specimen pigmentation was recorded.

NEONATES WITH SUSPECTED MECONIUM ILEUS

A single specimen of faeces $(n=26)$ or colostomy fluid $(n=4)$ was collected from a second group of 30 newborn babies between 3 and 21 days of age. The babies in this group had intestinal obstruction with clinical or radiological features, or both, suggesting meconium ileus. Specimens were obtained in each case by normal bowel action. In two babies in whom the initial chymotrypsin concentration was high in relation to the rest of the group, but still clearly subnormal when compared with the healthy neonates, follow up specimens were collected.

\section{ANALYTICAL METHODS}

Stool and colostomy fluid specimens (1-2 g) were collected in polystyrene Fecon stool containers and stored at $-20^{\circ} \mathrm{C}$ until analysed. Specimens from healthy neonates were accumulated until the baby went home so that all stools from a given baby were analysed in the same analytical batch. All analyses were completed within 14 days of collection.

Chymotrypsin activity was measured by the method of Haverback et al. ${ }^{6}$ Details of the procedure, together with method performance data, have been published previously. ${ }^{4}$

\section{STATISTICAL EVALUATION}

All statistical evaluations were non-parametric. The degree of association between two measurements and its significance was determined using Spearman's rank correlation coefficient. The significance of differences between groups was determined using the Mann-Whitney $U$ test.

\section{Results}

\section{HEALTHY NEONATES}

Individual stool chymotrypsin values (fig 1)

The random stool data from all 25 babies were grouped into 24 hour periods from birth. Chymotrypsin concentrations increased rapidly over the first $\mathbf{4 8}$ hours of life, then increased more slowly, reaching a peak in the fourth 24 hour period. Concentrations then fell back again, over the next four 24 hour periods, to the range seen in the first 24 hours of life. The peak was well defined in some babies but less so in others, presumably due to the random nature of the stool collection. The median chymotrypsin concentration of specimens passed in the first 24

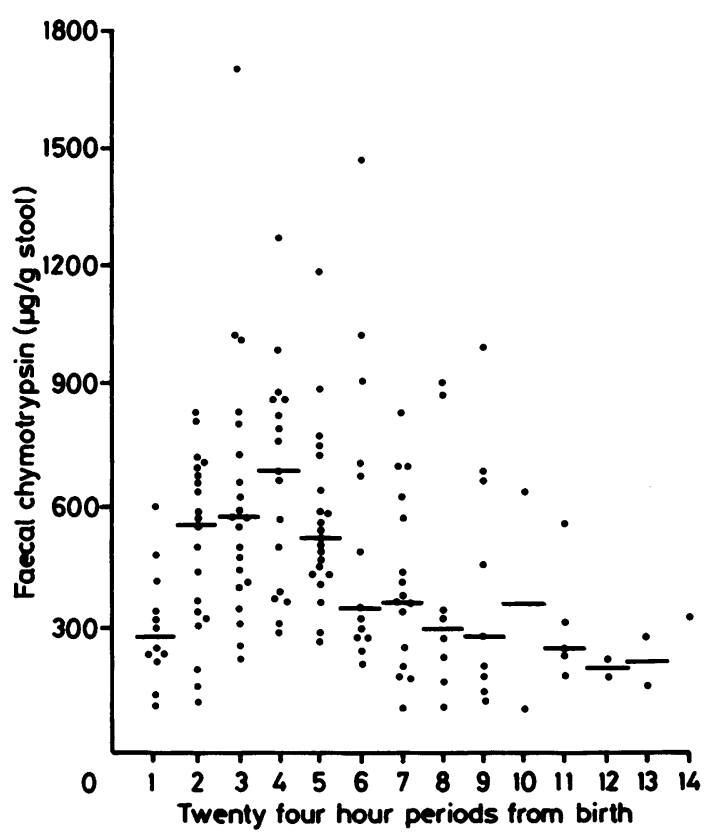

Fig 1 Random stool chymotrypsin concentrations in the 25 healthy babies. Results are grouped into 24 hour periods after birth. The horizontal bars show the median value for each interval.

hours after birth was $290 \mu \mathrm{g} / \mathrm{g}$ stool and the lowest concentration was $120 \mu \mathrm{g} / \mathrm{g}$ stool. The median value increased to $725 \mu \mathrm{g} / \mathrm{g}$ stool for the fourth 24 hour period with the lowest individual value being 305 $\mu \mathrm{g} / \mathrm{g}$ stool. Twenty four hour median values then declined over the remainder of the study period to about $200 \mu \mathrm{g} / \mathrm{g}$. The lowest value observed in this latter period was again, coincidentally, $120 \mu \mathrm{g} / \mathrm{g}$ stool.

The overall range of individual stool chymotrypsin activities from all 25 babies, over the period of 3-336 hours (14 days), was 120-1680 $\mu \mathrm{g} / \mathrm{g}$ stool. The results from one baby were excluded from this range. Initial values in this baby were unexceptional. They then increased to very high values, $(1880,2020$, and $1840 \mu \mathrm{g} / \mathrm{g}$ stool) during the second, third, and fourth 24 hour periods, falling finally to values similar to the rest of the group. A three month follow up on this baby did not disclose any abnormality.

The individual stool values from the seven preterm babies tended to be lower than the term babies, the highest preterm value being $1264 \mu \mathrm{g} / \mathrm{g}$ stool. At the lower end of the range values were similar with none of the preterm baby values falling below the lower end of the term baby range. 


\section{Mean stool chymotrypsin concentrations}

A mean chymotrypsin concentration was calculated for each baby using the data from stool specimens passed between birth and 8 days of age. The mean values in the term babies (range 345-888, median $581 \mu \mathrm{g} / \mathrm{g}$ stool) increased with increasing birth weight (fig 2) producing a significant positive correlation $(r=0.643, p<0.01)$. The mean value for the baby who produced extremely high individual stool values on days 2,3 , and 4 was greater than the mean plus 3 standard deviations for the remaining 17 term babies. Data from this baby therefore was not included in the birthweight correlation (fig 2), although inclusion still produced a significant value $(\mathrm{r}=0.487, \mathrm{p}<0.05)$.

Mean chymotrypsin concentrations in the seven preterm babies (range 262-678, median $392 \mu \mathrm{g} / \mathrm{g}$ stool) tended to be low with five at or below the median value for the whole group. They were not, however, significantly lower than the mean values of the term babies $(p=0.054)$. Only the lowest birthweight preterm baby had a mean value below the observed range of the term babies or a range expressed by the mean minus 2 standard deviations. Values in the light for dates babies were similar to those of the appropriate weight babies. Values for the breast fed babies were also unexceptional.

\section{Stool pigmentation}

The time of transition of specimen pigmentation varied. Yellow faecal pigmentation appeared as early as 48 hours in some babies while others produced meconium pigmented material as late as 120 hours after birth. The average time for the transition occurred at around the fourth 24 hour period, coinciding with peak chymotrypsin activity.

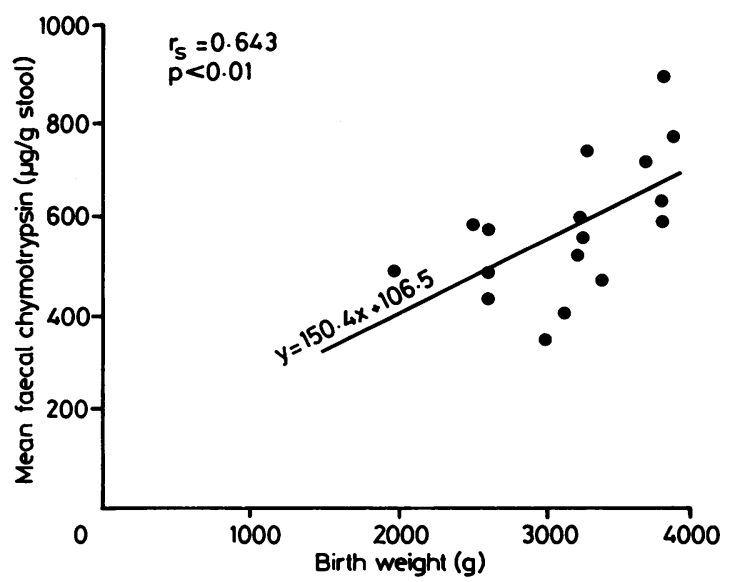

Fig 2 Correlation of birth weight with mean faecal chymotrypsin concentration in the term babies.
NEONATES WITH SUSPECTED MECONIUM ILEUS

The data for random stool chymotrypsin concentrations from this group in relation to the results of sweat tests done at 6 weeks of age or later are shown in fig 3.

\section{Sweat test positive babies}

In the 22 babies who had sweat electrolyte concentrations consistent with a diagnosis of cystic fibrosis, the two highest faecal chymotrypsin concentrations were $57 \%$ and $33 \%$ (68 and $48 \mu \mathrm{g} / \mathrm{g}$ stool) of the lowest value seen in the healthy neonates. Repeat testing in those two babies, one week after the initial observation, produced concentrations of $10 \%$ or less of the lowest normal value (12 and $8 \mu \mathrm{g} / \mathrm{g}$ stool). In the remaining 20 babies who had a positive sweat test, faecal chymotrypsin concentrations were $17 \%$ or less (median overall $6 \%$ ) of the lowest value in the healthy neonates. Activity was not detectable in seven.

In one of the two babies producing the high chymotrypsin concentrations, seven repeat observations were made between 3 and 16 days. The initial value at 3 days was $16 \mu \mathrm{g} / \mathrm{g}$ stool, the concentration rose to $48 \mu \mathrm{g} / \mathrm{g}$ on day 5 then decreased to nil by day

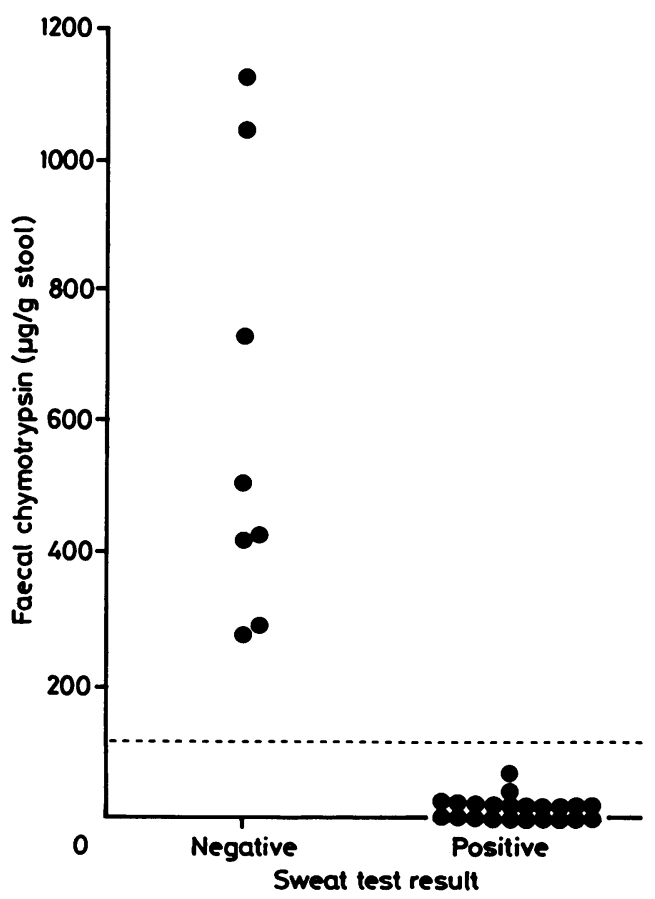

Fig 3 Single random stool chymotrypsin concentrations in babies either negative or positive for the sweat test. The broken line shows the lower limit of the observed range in the healthy neonates. 
13. This pattern was similar to that shown by the healthy neonates but at a much lower concentration level.

In the stool specimens from the babies with a positive sweat test that contained detectable concentrations of chymotrypsin, the 14 specimens passed before 10 days of age had significantly higher chymotrypsin concentrations $(p=0.025)$ than the 10 specimens passed between 10 and 20 days.

\section{Sweat test negative babies}

In the eight babies whose sweat electrolytes were normal, the chymotrypsin concentrations, including the single colostomy specimen in this group, were well within the faecal chymotrypsin normal range, the lowest value being $275 \mu \mathrm{g} / \mathrm{g}$ stool.

\section{Discussion}

In the healthy neonates faecal chymotrypsin concentrations varied with the age of the baby over the first 8 days of life. The lower limit of the range also varied over the same period but the lowest concentration at any time during the study was $120 \mu \mathrm{g} / \mathrm{g}$ stool and this has been adopted as the lower limit of the observed range for healthy neonates.

The lower mean faecal chymotrypsin concentrations in the preterm babies were in accord with intraduodenal observations already reported that pancreatic exocrine secretory activity in the preterm baby is reduced compared with the term baby. ${ }^{78}$ Pancreatic function has not been shown to be different in light for dates or breast fed babies and the faecal chymotrypsin concentrations were not obviously different in babies in either category in this study.

The higher faecal chymotrypsin concentrations in the higher birthweight babies suggested greater pancreatic activity. This may have been an inherent feature but it may also have been due to the feeding regime, the heaviest babies receiving almost twice the protein intake of the lightest. Large increases in protein intake increase intraduodenal enzyme concentrations. ${ }^{9}$

The very high values seen in one of the healthy neonates remain unexplained. They may have been normal but appeared otherwise because of the relatively small size of the group investigated. Alternatively, they may have been the result of a brief phase of greatly increased pancreatic activity. Further work with this non-invasive test is indicated. It may produce information about the physiological modulation of pancreatic function that would be unobtainable by intraduodenal testing.

Little data on neonatal faecal chymotrypsin concentrations have been published for comparison.
Mullinger and Palasi also found increasing faecal chymotrypsin concentrations during the first 3 days of life, but, unlike those reported in our data they rose further on days 6 and 7.5 In a more recent study reporting chymotrypsin concentrations in the stool aqueous phase of the preterm neonate, concentrations decreased between 1 and 2 weeks of age. ${ }^{10}$ Direct comparison with our data from whole stool homogenate is difficult as most of the chymotrypsin activity was firmly bound to the solid phase. The decreasing activity described in the 2 nd week of life and the lower concentration at this age, however, compared with older infants, is consistent with our findings.

A similar pattern of changing concentration has been reported for pancreozymin stimulated duodenal enzymes in the neonate ${ }^{7}$ for gastric acid concentration, ${ }^{11}$ and for plasma gastrin and enteroglucagon concentrations. ${ }^{12}$ This coinciding, similar surge of endocrine and exocrine activity in the first few days of life appears to be a part of the initial endocrine-exocrine response to the introduction of enteral feeding. The early high gut enzyme concentration may result in more efficient mobilisation and elimination of the meconium, the peak faecal enzyme concentration at 4 days of age coinciding with the change from meconium to faecal pigmentation of the stools.

The duodenal-faecal enzyme relation in the healthy neonate appears to be sufficiently close for the subtle perinatal changes in pancreatic function to be shown by faecal chymotrypsin measurements and the latter may therefore be useful in other physiological or nutritional studies.

Chymotrypsin concentrations were grossly subnormal in all 22 babies subsequently shown to have cystic fibrosis. We do not have reference values for chymotrypsin concentrations in colostomy fluid but the concentrations in the three colostomy fluid samples from babies with a positive sweat test and the single colostomy fluid from a baby with a negative sweat test were in the same ranges as the faecal concentrations from those groups. We consider them therefore to be of similar importance to the faecal measurements in this context.

The two highest chymotrypsin concentrations in the babies with cystic fibrosis were produced at ages of 5 and 6 days respectively, that is, close to the time of peak concentration in the healthy neonates. On repeat testing a few days later the concentrations had fallen to the very low concentrations more characteristic of cystic fibrosis. Where intermediate values are found therefore, particularly in the first week of life, repeat testing is essential.

The full clinical value of faecal chymotrypsin measurement in the neonate remains to be deter- 
mined. The concentrations seen in the babies with cystic fibrosis in this study indicate gross pancreatic exocrine insufficiency and concentrations presumably would be similar in the other inborn errors characterised by profound pancreatic exocrine insufficiency, although the non-cystic fibrosis disorders are very rare. Absence of chymotryptic activity may also result from a functional or anatomic defect preventing transit, or extremely rarely, enterokinase deficiency. Where cystic fibrosis is suspected, however, absence of faecal chymotrypsin would be a strong indicator in favour of the diagnosis and such information would be available several weeks in advance of a sweat test result. Despite its value in this particular context, however, it must be remembered that faecal chymotrypsin is a measure of pancreatic function and not a screening test for cystic fibrosis.

Faecal enzyme measurements are likely to give a less accurate assessment of pancreatic exocrine activity than the more direct intraduodenal tests. This study and our earlier investigations have shown, however, that the duodenal-faecal relation is sufficiently close for many of the questions asked about pancreatic function in the neonate to be answered by faecal studies. ${ }^{4}$ Compared with intraduodenal testing, faecal chymotrypsin measurements have the additional advantages of being noninvasive, rapid, simple, inexpensive, and repeatable as often as required.

We are most grateful for the help given by Sister Sallis and her staff at the Sorrento Special Care Baby Unit where all stool collections were made and recorded. We also thank Dr BA Wharton, consultant paediatrician, who approved the investigation of babies in his care. PJ Turner was supported by a grant from the Endowment Fund of the former United Birmingham Hospitals.
References

${ }^{1}$ Sale JK, Goldberg DM, Thjodleifsson B, Wormsley KB. Trypsin and chymotrypsin in duodenal aspirates and faeces in response to secretin and cholecystokinin-pancreozymin. Gut 1974;15:132-8.

2 Durr HK, Otte M, Forell MM, Bode JC. Faecal chymotrypsin: a study on its diagnostic value by comparison with the secretincholecystokinin test. Digestion 1978;17:404-9.

${ }^{3}$ Lami F, Calligari C, Miglioli M, Barbara L. A single fecal chymotrypsin test in the diagnosis of pancreatic insufficiency: correlation with secretin-cholecystokinin and NBT-PABA tests. Am J Gastroenterol 1984;79:697-700.

4 Brown GA, Sule D, Williams J, Puntis JWL, Booth IW, McNeish AS. Faecal chymotrypsin: a reliable index of exocrine pancreatic function. Arch Dis Child 1988;63:785-9.

5 Mullinger M, Palasi M. Tryptic and chymotryptic activity of stools of newborn infants. Pediatrics 1966;38:657-9.

6 Haverback BJ, Dyce BJ, Gutentag PJ, Montgomery DW. Measurement of trypsin and chymotrypsin in stool: a diagnostic test for pancreatic exocrine insufficiency. Gastroenterology $1963 ; 44: 588-97$.

7 Zoppi G, Andreotti G, Pajno-Ferrara F, Njai DM, Gabburo D. Exocrine pancreatic function in premature and full-term neonates. Pediatr Res 1972;6:880-6.

${ }^{8}$ Borgstrom B, Lindquist B, Lundh G. Enzyme concentration and absorption of protein and glucose in the duodenum of premature infants. Am J Dis Child 1962;99:338-43.

9 Zoppi G. Feeding and postnatal development of exocrine pancreatic function. In: Muller HB, Secretin MC, eds. Enzyme development and postnatal feeding. Nestlé Symposium, Lausanne: Nestle, 1975:89-97.

10 Bhavani S, Eggermont E, Standaert L, De Cock P, Cardon H. Stool chymotrypsin in the preterm infant. Acta Paediatr Belg 1979;32:51-3.

11 Kayal RK, Subhash CG, Vimla VK, Nidam S. A study of gastric acid in newborns. Indian Pediatr 1979;16:1127-31.

12 Lucas A, Adrian TE, Christophides N, Bloom SR, AynesleyGreen A. Plasma motilin, gastrin and enteroglucagon and feeding in the human newborn. Arch Dis Child 1980;55:673-7.

Correspondence to Mr GA Brown, Institute of Child Health, Francis Road, Birmingham B16 8ET.

Accepted 8 March 1988 